\title{
The Relevance of Hyperuricemia and Metabolic Syndrome and the Effect of Blood Lead Level on Uric Acid Concentration in Steelmaking Workers
}

\author{
Deul Lee, Won-Jun Choi, Jae-Seok Oh, Min-Kee Yi, Sung-Woo Han, Jong-Wan Yun and Sang-Hwan Han*
}

\begin{abstract}
Objectives: Uric acid concentration is known to increase the prevalence of metabolic syndrome by affecting its components, resulting in increased risk of cerebrovascular and cardiovascular diseases, and long-term lead exposure is known to affect this serum uric acid level. In this study, we aimed to examine the association between the causes of hyperuricemia and metabolic syndrome, and to determine whether an increased blood lead level affects hyperuricemia.
\end{abstract}

Method: Anthropometric measurements, surveys, and blood tests were conducted between May and June 2012 in 759 men working in the steelmaking process at a domestic steel company. Workers were divided into 2 groups according to the presence or absence of hyperuricemia, and an analysis was performed to examine its association with metabolic syndrome. In addition, the workers were divided into 3 groups according to the blood lead level to analyze the association between blood lead and hyperuricemia.

Results: The geometric mean (standard deviation) of the blood lead levels in the hyperuricemia group was significantly higher than that of the healthy group (3.8 [1.8] vs. $3.3[1.8] \mu \mathrm{g} / \mathrm{dL}$ ). The adjusted odds ratio for metabolic syndrome of the hyperuricemia group increased significantly to 1.787 (1.125-2.839) compared with the healthy group. In addition, the adjusted odds ratios for the occurrence of hyperuricemia in the tertile $2(2.61-4.50 \mu \mathrm{g} / \mathrm{dL})$ and tertile 3 groups (>4.50 $\mu \mathrm{g} / \mathrm{dL}$ ) according to blood lead level significantly increased to $1.763(1.116-2.784)$ and 1.982 (1.254-3.132), respectively, compared with the tertile 1 group $(<2.61 \mu \mathrm{g} / \mathrm{dL})$.

Conclusion: Hyperuricemia is believed to function as an independent risk factor for metabolic syndrome, while lead seems to increase the serum uric acid level even at a considerably low blood level. Therefore, attention should be given to patients with hyperuricemia and metabolic syndrome who are prone to lead exposure, and a prospective study should be conducted to identify their causal relationship.

Keywords: Lead, Uric acid, Metabolic syndrome

\section{Introduction}

According to the 2011 Statistics Korea data on domestic causes of death, cerebrovascular and heart diseases ranked second and third, respectively, among the 3 leading causes of death in Korea as yet [1]. Moreover, according to a report, 278 of 731 occupational disease-related deaths in 2011 were due to cerebrovascular and cardiovascular diseases [2]. As such, the prevention of occupational cerebrovascular and cardiovascular diseases is gaining

\footnotetext{
* Correspondence: hansh@gachon.ac.kr

Department of Occupational \& Environmental Medicine, Gachon University

Gil Medical Center, Incheon, Korea
}

importance along with continuous efforts of many businesses and health institutions to develop practical preventive measures through the management of metabolic syndromes that involve various cerebrovascular and cardiovascular risk factors.

Various studies have identified metabolic syndromes as a major predictor of cerebrovascular and cardiovascular diseases [3], and study results indicated that the occurrence and progression of cerebrovascular and cardiovascular diseases can be prevented through strict management of metabolic syndrome [4]. 
Recently, continuous reports have emerged on the association between metabolic syndrome, cerebrovascular and cardiovascular diseases, and serum uric acid level, which is well known to be a causal factor for gout. Gradually accumulated evidence support that serum uric acid level has a significant correlation with each component of a metabolic syndrome, as it causes hypertension and insulin resistance and is involved in changes in blood triglycerides and cholesterol levels while being associated with obesity and complications of metabolic syndromes $[5,6]$.

Existing studies conducted with the general population or workers reported their analysis results that hyperuricemia significantly correlated with blood lead concentrations [7]. Meanwhile, the results of other studies verified relatively high serum uric acid levels and high incidence rates of gout in people with long-term lead exposure [8,9]; as such, an integrated approach for the management of long-term lead exposure and hyperuricemia, as well as metabolic syndrome, is necessary from the perspective of occupational environment medicine.

Until the present, only a few domestic studies have analyzed the relationship between hyperuricemia and metabolic syndrome; in particular, it is difficult to find domestic and international case studies analyzing the relationship between occupational lead exposure, hyperuricemia, and metabolic syndrome. Therefore, this study aimed to examine the relationship between blood lead level and serum uric acid concentration, and the association between hyperuricemia and the occurrence of metabolic syndrome in male workers involved in steelmaking [10], which requires the most number of lead handling processes among metal industries.

\section{Materials and methods Subject}

Health screenings were conducted for a domestic steelmaker between May 15 and June 5, 2012, in which 2,133 of total 2,157 target workers were screened. Among the target workers, most were male workers, accounting for 2,097 subjects $(97.2 \%), 765$ (36.5\%) of whom were working in the steelmaking process. Among them, 759 male workers participated in the survey. Excluding the 6 male steelmaking workers who did not participate in the anthropometry or blood testing or who provided inadequate responses to the survey, a total of 759 workers were finally selected as research subjects.

\section{Anthropometric measurements and surveys}

Height and weight were measured using an automatic body measurement device, and a tape measure was used to measure the waist circumference on the midpoint between the bottom part of the ribs and the upper part of the pelvic bones horizontal to the ground. Blood pressure was measured using an automatic blood pressure measuring system after more than 5 minutes of steady state; when the systolic and diastolic pressures were 140 and $90 \mathrm{~mm}$ $\mathrm{Hg}$ or higher, respectively, the lower value was selected after a repeated measurement taken after more than 10 minutes of rest. Body mass index (BMI) was calculated by dividing weight $(\mathrm{kg})$ by the square of height $(\mathrm{m})$.

Through a self-reported survey, medical history of hypertension, diabetes, and dyslipidemia, and the use of medication therapy, smoking and drinking habits, and exercise, were examined. Survey data on smoking and drinking habits (considering the different types of alcohol) were presented in pack-years and days/week, respectively. Exercise was defined as a minimum of 20 minutes of workout per day until feeling out of breath and was expressed in frequency (days/week).

\section{Blood and urine tests}

After at least 8 hours of fasting, venous blood samples were collected from the subjects and fasting glucose, total cholesterol, triglyceride, high-density lipoprotein (HDL) cholesterol, aspartate aminotransferase (AST), alanine aminotransferase (ALT), $\gamma$-glutamic transpeptidase $(\gamma$-GTP), creatinine, blood lead, and serum uric acid concentrations were measured. The blood lead concentration analysis was performed using atomic absorption spectrophotometry (AAnalyst 600, PerkinElmer, Finland), and serum uric acid concentration was measured using Uricase EMST method (Hitachi 747 automatic analyzer, Hitachi, Tokyo, Japan). For low-density lipoprotein (LDL) cholesterol, the value calculated using the Friedewald formula, LDL $(\mathrm{mg} / \mathrm{dL})=\mathrm{TC}(\mathrm{mg} / \mathrm{dL})-\mathrm{HDL}(\mathrm{mg} / \mathrm{dL})-\mathrm{TG}$ $(\mathrm{mg} / \mathrm{dL}) / 5$, was used when the triglyceride level was lower than $400 \mathrm{mg} / \mathrm{dL}$ and the direct measurement method through the homogenous method was used if the triglyceride level exceeded $400 \mathrm{mg} / \mathrm{dL}$.

\section{Definition of metabolic syndrome}

By applying the criteria of the American Heart Association/ National Heart Lung and Blood Institute published in 2005 [11], metabolic syndrome was defined when 3 or more of the following 5 risk factors were applicable: (1) waist circumference of $90 \mathrm{~cm}$ or greater, (2) blood triglyceride concentrations of $150 \mathrm{mg} / \mathrm{dL}$ or higher or being under medication therapy, (3) blood HDL level lower than $40 \mathrm{mg} / \mathrm{dL}$ or being under medication therapy, (4) systolic pressure of $130 \mathrm{~mm} \mathrm{Hg}$ or higher or diastolic pressure of $85 \mathrm{~mm} \mathrm{Hg}$ or higher or being under medication therapy, and (5) fasting glucose level of $100 \mathrm{mg} / \mathrm{dL}$ or higher or being under medication therapy.

\section{Statistical analysis}

Statistical analysis was performed using SPSS (version 18.0). Hyperuricemia was defined as a serum uric acid 
concentration of higher than $7.0 \mathrm{mg} / \mathrm{dL}$ [12], and a $t$ test was performed to determine whether a hyperuricemiadependent difference existed in the anthropometric measurements, blood test results, and living habits. As blood lead concentration showed a distribution skewed to the left, geometric means and standard deviations were calculated after performing natural log transformation. To analyze the relationship between hyperuricemia and metabolic syndrome, we performed a logistic regression analysis. For variables other than hyperuricemia, a multivariate logistic regression analysis was performed by including them in the model as confounding variables after confirming multicollinearity. In addition, the relationship between blood lead concentration and hyperuricemia was analyzed. Blood lead concentration was set as an explanatory variable by classifying it in tertiles, and a multivariate logistic regression analysis was performed by including them in the model as confounding variables after confirming multicollinearity among other variables, excluding the components of metabolic syndrome.

\section{Results}

\section{Hyperuricemia-dependent clinical characteristics of the} subjects

The healthy (without hyperuricemia) group had 577 subjects, and the hyperuricemia group had 182 subjects. The mean (standard deviation) for serum uric acid concentration was $5.5(0.9) \mathrm{mg} / \mathrm{dL}$ in the healthy group and 7.8 (0.7) $\mathrm{mg} / \mathrm{dL}$ in the hyperuricemia group (Table 1). Compared with the healthy group, the mean age was significantly lower and the mean waist circumference and BMI were significantly higher in the hyperuricemia group. In the hyperuricemia group, fasting glucose and HDL-cholesterol levels were significantly lower, whereas triglycerides, AST, ALT, $\gamma$-GTP, and serum creatinine levels were significantly higher compared to those in the healthy group. Weekly drinking frequency was significantly higher but weekly exercise frequency was significantly lower in the hyperuricemia group than in the healthy group. The geometric mean (standard deviation) of the blood lead concentrations was significantly higher in the hyperuricemia group, at $3.8(1.8) \mu \mathrm{g} / \mathrm{dL}$, than in the healthy group, at $3.3(1.8) \mu \mathrm{g} / \mathrm{dL}$.

\section{Relationship between hyperuricemia and the occurrence of metabolic syndrome}

Hyperuricemia was found to be significantly associated with the occurrence of metabolic syndrome through the univariate (model 1; Table 2) and multivariate logistic regression analyses, the latter being adjusted for age and blood lead concentration (model 2); additionally adjusted for smoking, drinking, and exercise habits (model 3); and for LDL-cholesterol, $\gamma$-GTP, and serum creatinine
Table 1 Hyperuricemia-dependent clinical characteristics of the subjects

\begin{tabular}{|c|c|c|c|c|c|}
\hline \multirow{3}{*}{$\begin{array}{l}\text { Variables } \\
\text { Age (years) }\end{array}$} & \multirow{2}{*}{\multicolumn{2}{|c|}{$\begin{array}{c}\begin{array}{c}\text { Normal } \\
(\mathrm{N}=577)\end{array} \\
\text { Mean (SD) }\end{array}$}} & \multirow{2}{*}{\multicolumn{2}{|c|}{$\begin{array}{c}\begin{array}{c}\text { Hyperuricemia }^{\dagger} \\
(\mathrm{N}=182)\end{array} \\
\text { Mean (SD) }\end{array}$}} & \multirow{3}{*}{$\begin{array}{c}\text { p-value } \\
0.000^{*}\end{array}$} \\
\hline & & & & & \\
\hline & 42.3 & $(10.9)$ & 38.1 & $(10.3)$ & \\
\hline Waist circumference $(\mathrm{cm})$ & 83.5 & $(7.2)$ & 85.5 & (7.5) & $0.001^{*}$ \\
\hline Body mass index $\left(\mathrm{kg} / \mathrm{m}^{2}\right)$ & 24.1 & (2.6) & 24.9 & (2.9) & $0.001^{*}$ \\
\hline $\begin{array}{l}\text { yystolic blood } \\
\text { pressure }(\mathrm{mmHg})\end{array}$ & 118.3 & $(12.1)$ & 119.8 & $(11.5)$ & 0.135 \\
\hline $\begin{array}{l}\text { Diastolic blood } \\
\text { pressure }(\mathrm{mmHg})\end{array}$ & 76.2 & (9.7) & 77.4 & (9.8) & 0.142 \\
\hline $\begin{array}{l}\text { Fasting blood } \\
\text { glucose (mg/dL) }\end{array}$ & 98.5 & $(21.4)$ & 94.0 & $(11.5)$ & $0.000^{*}$ \\
\hline Total cholesterol (mg/dL) & 194.0 & (34.6) & 199.7 & $(34.9)$ & 0. \\
\hline LDL-cholesterol (mg/dL) & 110.0 & $(30.7)$ & 110.6 & (34.8) & 0.829 \\
\hline HDL-cholesterol (mg/dL) & 54.0 & $(11.9)$ & 51.1 & $(10.9)$ & $0.004^{*}$ \\
\hline Triglyceride (mg/dL) & 157.0 & $(116.0)$ & 209.0 & $(161.4)$ & $0.000^{*}$ \\
\hline$\overline{\text { AST (IU/L) }}$ & 24.5 & (13.3) & 28.7 & $(14.7)$ & $0.001^{*}$ \\
\hline$\overline{\mathrm{ALT}(\mathrm{IU} / \mathrm{L})}$ & 27.4 & $(25.8)$ & 35.2 & $(27.3)$ & $0.001^{*}$ \\
\hline Y-GTP (IU/L) & 44.0 & $(46.7)$ & 59.2 & $(60.8)$ & $0.002^{*}$ \\
\hline Serum creatinine $(\mathrm{mg} / \mathrm{dL})$ & 0.9 & $(0.1)$ & 1.0 & $(0.1)$ & $0.000^{*}$ \\
\hline Smoking (pack-year) & 10.7 & $(11.9)$ & 11.2 & $(11.6)$ & 0.622 \\
\hline Drinking (days/week) & 1.7 & (1.9) & 1.9 & (1.3) & $0.037^{*}$ \\
\hline Exercise (days/week) & 1.8 & $(1.7)$ & 1.5 & (1.7) & $0.029^{*}$ \\
\hline Blood lead $(\mu \mathrm{g} / \mathrm{dL})^{\ddagger}$ & 3.3 & $(1.8)$ & 3.8 & (1.8) & $0.003^{*}$ \\
\hline
\end{tabular}

: $p<0.05$ by t-test.

: Serum uric acid level $\geq 7 \mathrm{mg} / \mathrm{dL}$

‡: Geometric mean (Geometric standard deviation).

levels (model 4). In addition, age and $\gamma$-GTP level were found to be significantly associated with metabolic syndrome.

\section{Association between blood lead concentration and the occurrence of hyperuricemia}

In the univariate logistic regression analysis (model 1), the odds ratio for hyperuricemia increased as the blood lead concentration increased in relation to 1 quartile (Table 3). Blood lead concentration was found to have a significant association with hyperuricemia in the multivariate logistic regression analysis models respectively adjusted for age, BMI, and $\gamma$-GTP level (model 2); additionally adjusted for smoking, drinking, and exercise habits (model 3); and adjusted for serum creatinine (model 4). In addition, a significant association was observed between hyperuricemia, and BMI, $\gamma$-GTP level, smoking habit, and serum creatinine level, among which serum creatinine level particularly showed a high odds ratio of 16.877 , indicating a very high degree of association with hyperuricemia. 
Table 2 Multiple logistic regression analysis demonstrating relationship between hyperuricemia and metabolic syndrome ${ }^{*}$ in four models

\begin{tabular}{|c|c|c|c|c|}
\hline \multirow[t]{2}{*}{ Variables } & \multicolumn{4}{|c|}{ Odds ratio (95\% confidence interval) } \\
\hline & Model 1 & Model 2 & Model 3 & Model 4 \\
\hline \multicolumn{5}{|l|}{ Hyperuricemia ( $\geq 7$ mg/dL) } \\
\hline No & 1.000 & 1.000 & 1.000 & 1.000 \\
\hline Yes & $1.533(1.014 \sim 2.317)$ & $2.016(1.296 \sim 3.135)$ & $1.939(1.242 \sim 3.026)$ & $1.787(1.125 \sim 2.839)$ \\
\hline Age (years) & & $1.057(1.037 \sim 1.077)$ & $1.055(1.032 \sim 1.077)$ & $1.049(1.026 \sim 1.073)$ \\
\hline log transformed blood lead ( $\mu \mathrm{g} / \mathrm{dL})$ & & $0.855(0.414 \sim 1.768)$ & $0.822(0.394 \sim 1.715)$ & $0.789(0.370 \sim 1.681)$ \\
\hline Smoking (pack-year) & & & $1.007(0.991 \sim 1.024)$ & $1.005(0.988 \sim 1.022)$ \\
\hline Drinking (days/week) & & & $1.035(0.906 \sim 1.183)$ & $0.948(0.820 \sim 1.097)$ \\
\hline Exercise (days/week) & & & $0.941(0.837 \sim 1.057)$ & $0.969(0.861 \sim 1.091)$ \\
\hline LDL-cholesterol (mg/dL) & & & & $1.002(0.996 \sim 1.008)$ \\
\hline $\mathrm{Y}$-GTP (IU/L) & & & & $1.008(1.005 \sim 1.012)$ \\
\hline Serum creatinine $(\mathrm{mg} / \mathrm{dL})$ & & & & $0.433(0.077 \sim 2.442)$ \\
\hline
\end{tabular}

\section{Discussion}

This study examined the association between hyperuricemia and metabolic syndrome, and the association between blood lead and serum uric acid concentrations. Hyperuricemia showed a significant association with metabolic syndrome even in the results adjusted for confounding variables, whereas lead was shown to be associated with hyperuricemia even at low blood concentrations.
According to existing studies [13,14], an increase in serum uric acid concentration is thought to partially contribute to an increase in blood pressure via the activation of the renin-angiotensin-aldosterone system by inducing renal vascular inflammation, preglomerular arteriolopathy, tubulointerstitial inflammation and fibrosis. Serum uric acid concentration also seems to interfere with blood vessel expansion by decreasing the response of blood vessels

Table 3 Multiple logistic regression analysis demonstrating association between blood lead level and hyperuricemia in four models

\begin{tabular}{|c|c|c|c|c|}
\hline \multirow[t]{2}{*}{ Variables } & \multicolumn{4}{|c|}{ Odds ratio (95\% confidence interval) } \\
\hline & Model 1 & Model 2 & Model 3 & Model 4 \\
\hline \multicolumn{5}{|c|}{ Tertile group (blood lead, $\mu \mathrm{g} / \mathrm{dL}$ ) } \\
\hline I $(<2.61)$ & 1.000 & 1.000 & 1.000 & 1.000 \\
\hline II (2.61 4.50) & $1.676(1.091 \sim 2.576)$ & $1.971(1.258 \sim 3.087)$ & $1.902(1.211 \sim 2.989)$ & $1.763(1.116 \sim 2.784)$ \\
\hline III (>4.50) & $1.890(1.236 \sim 2.889)$ & $2.286(1.460 \sim 3.579)$ & $2.182(1.389 \sim 3.430)$ & $1.982(1.254 \sim 3.132)$ \\
\hline Age (years) & & $0.951(0.934 \sim 0.967)$ & $0.943(0.924 \sim 0.962)$ & $0.945(0.925 \sim 0.965)$ \\
\hline Body mass index $\left(\mathrm{kg} / \mathrm{m}^{2}\right)$ & & $1.098(1.031 \sim 1.168)$ & $1.099(1.033 \sim 1.170)$ & $1.096(1.030 \sim 1.168)$ \\
\hline$\gamma$-GTP (IU/L) & & $1.006(1.003 \sim 1.010)$ & $1.005(1.002 \sim 1.009)$ & $1.005(1.002 \sim 1.009)$ \\
\hline Smoking (pack-year) & & & $1.017(0.999 \sim 1.035)$ & $1.020(1.002 \sim 1.039)$ \\
\hline Drinking (days/week) & & & $1.076(0.944 \sim 1.226)$ & $1.085(0.951 \sim 1.238)$ \\
\hline Exercise (days/week) & & & $0.950(0.853 \sim 1.058)$ & $0.938(0.841 \sim 1.046)$ \\
\hline Serum creatinine $(\mathrm{mg} / \mathrm{dL})$ & & & & $16.877(3.388 \sim 84.073$ \\
\hline
\end{tabular}

*: Serum uric acid level $\geq 7 \mathrm{mg} / \mathrm{dL}$.

Model 1: not adjusted.

Model 2: adjusted by age, body mass index, $y$-GTP.

Model 3: adjusted for model 2 plus smoking, drinking, exercise.

Model 4: adjusted for model 3 plus serum creatinine. 
to acetylcholine and to increase blood pressure by causing endothelial dysfunction through interference in the excretion process of nitric oxide (NO) from vascular endothelial cells by expressing toxicity directly on the blood vessels $[15,16]$. In this regard, a study reported that when the activity of xanthine oxidase, which is involved in the uric acid generation process, was inhibited by administering allopurinol to patients, blood flow was improved along with vasodilation [17].

Whether serum uric acid level independently influences the increase in blood glucose level is controversial. While there are reports on increased insulin resistance due to certain serum uric acid levels increasing blood flow and causing vasodilation to interfere with the action of nitric oxide, which facilitates glucose absorption [18], other results suggest that hyperuricemia is caused by hyperinsulinemia due to insulin resistance acting on the renal tubules to facilitate the reabsorption of uric acid $[19,20]$. These results suggest an interaction between uric acid and insulin levels. However, the mean fasting glucose level in the hyperuricemia group was significantly lower than that in the healthy group in this study, contradicting the results of existing studies. Upon considering the results of recent related studies, a decreased fasting glucose level in patients with hyperuricemia is possibly due to the increase in uric acid excretion caused by the glomerular hyperfiltration when hyperglycemia is maintained $[21,22]$. However, additional research is necessary in the future to validate this hypothesis.

The effects of serum uric acid level on dyslipidemia have not yet been clearly identified; however, according to recent studies, the increase in uric acid concentration seems to reduce the function of lipid peroxidase and lipoprotein lipase, which are involved in lipolysis, while the process of decreased nitric oxide excretion from blood vessels is believed to affect the progression of dyslipidemia $[23,24]$. In this study, the total cholesterol and LDL-cholesterol levels in the hyperuricemia group were not statistically significant, but the mean levels were still higher compared to those in the healthy group. Meanwhile, triglyceride levels were significantly higher in the hyperuricemia group, with significantly lower HDLcholesterol levels, than in the healthy group. In particular, the levels of the triglycerides related to metabolic syndrome showed the greatest difference in mean values when compared with the other parameters, which seems to be due to the decreased function of the tricarboxylic acid cycle with the increased oxidative stress in the mitochondria of liver cells as the uric acid synthesis increased due to purine metabolism, resulting in slower triglyceride metabolism and an increase in lipogenesis [25].

Regarding the association between obesity and serum uric acid concentration, it is known that obese individuals mostly consume meat, with high intake of purine, which results in an increase in uric acid concentration [26], and hyperuricemia is caused by the facilitation of uric acid reabsorption in the renal tubules due to high insulin resistance. These results point to obesity as the cause of hyperuricemia [27,28]. However, based on the various correlations identified so far, such as the close association between insulin resistance and nitric oxide synthesis dysfunction in vascular endothelial cells and the claim that uric acid interferes with the nitric oxide excretion process [18], the increase in the risk for fatty liver in proportion to the purine metabolism-induced uric acid synthesis triggered by the deterioration in mitochondria function in liver cells [25], and the contribution of the reduced mitochondria functioning to the fat accumulation in muscles and liver in a study with a non-obese elderly population [29], hyperuricemia itself seems to partially contribute to obesity. This finding warrants additional research in the future.

In this study, the hyperuricemia group showed a significantly higher mean blood lead concentration than that in the healthy group. The subjects' geometric mean (standard deviation) blood lead concentration was approximately $3.4(1.8) \mu \mathrm{g} / \mathrm{dL}$, which was significantly lower than $25.0 \mu \mathrm{g} / \mathrm{dL}$ [30], the blood lead concentration designated by the Centers for Disease Control and Prevention $(\mathrm{CDC})$ as affecting the physiological health of adults, and even below the recommended upper limit level of $5.0 \mu \mathrm{g} / \mathrm{dL}$ for children in 2012 [31]. However, in our univariate and multivariate regression analyses, the risk of hyperuricemia was shown to increase even at low blood lead concentrations between 2.61 and $4.50 \mu \mathrm{g} / \mathrm{dL}$.

Uric acid is synthesized through the metabolism of purine, and humans are known to have a relatively high level of serum uric acid concentration compared with other mammals, as humans do not possess the enzyme for metabolizing uric acid [32]. Therefore, to maintain an appropriate level of serum uric acid, males need to excrete a daily volume of $600-700 \mathrm{mg}$ of uric acid through the glomeruli, and proximal and distal tubules of the kidney; ascending loop; and collecting duct. If kidney functioning is reduced, the probability of hyperuricemia becomes relatively high [33]. Furthermore, in this study, serum creatinine level and hyperuricemia showed a positive association, which is consistent with the existing study results that renal functioning affects serum uric acid levels.

In fact, according to recent studies, an increase in blood lead concentration caused a reduction in estimated glomerular filtration rate (eGFR) even at a blood lead concentration lower than $10.0 \mu \mathrm{g} / \mathrm{dL}$ [34]. In addition to the glomeruli, blood lead causes the atrophy and hyperplasia of the tubular epithelial cells and increases the risk for hyperuricemia by reducing secretory functions to cause interstitial fibrosis and inflammation [7,35,36]. In 
addition, when blood lead concentration is higher than $1.2 \mu \mathrm{g} / \mathrm{dL}$, the risk for gout reportedly increases with the reduction in uric acid excretion ability of the kidney [37].

An independent association with hyperuricemia was observed for smoking and $\gamma$-GTP level; however, it is too early to assume that both are direct risk factors for hyperuricemia, as existing studies report inconsistent results, suggesting the need to conduct a prospective study [38-40].

The steelmaking company investigated in this study was an independent steelmaker largely divided into steelmaking and rolling processes. The steelmaking process exposes workers to lead fumes during the dissolving process, during which metal containing impurities is melted [41]. In fact, according to a study that measured ambient lead concentration using individual samples during the steelmaking process, most of the samples showed lead concentrations exceeding $50 \%$ of the domestic threshold $\left(0.05 \mathrm{mg} / \mathrm{m}^{3}\right)$, indicating that the steelmaking process require attention regarding occupational lead exposure, along with the iron making process, in which metal is extracted by dissolving ore [41-43]. In addition, the workers involved in ironmaking processes were exposed to mineral dust, noise, hyperthermia, sulfur dioxide $\left(\mathrm{SO}_{2}\right)$, carbon monoxide (CO), and hydrogen sulfide $\left(\mathrm{H}_{2} \mathrm{~S}\right)$, but none of the causative factors of hyperuricemia identified by previous studies was found.

This study has its significance in providing results that controlled task properties and sex by limiting the subjects to male workers from a steelmaking company known to have the most number of lead handling processes among other metal industries, in comparison with existing studies that did not match task properties while targeting the general public or workers as subjects. It is also significant in that its simultaneous analyses revealed that hyperuricemia is significantly associated with metabolic syndrome and that low levels of blood lead can affect hyperuricemia.

This study has the following limitations: First, it is a cross-sectional study, and a causal relationship between blood lead level, serum uric acid level, and metabolic syndrome could not be established while attempting to explain the intervariable relationships using various studies in the existing literature. Second, recall bias might have existed, as the smoking, drinking, and exercise habits, and drug therapy were examined through surveys; this bias was minimized through the comparison between existing survey data for identical subjects. Third, no survey was conducted on diet related to serum uric acid concentration; it was partially controlled as the workers took the same meal twice a day at the company canteen while working 3 shifts, but a more accurate investigation needs to be conducted. Lastly, as it is an analysis for a particular group, our study was limited in generalizing the results to all population groups. In a group without occupational exposure, identical physiological mechanisms due to blood lead levels were reported [44]. However, a study with a general population group is needed in the future.

At present, with the prevention and management of workplace workers' cerebrovascular and cardiovascular diseases becoming increasingly important, attention should be given to serum uric acid concentration, which has been regarded as a causal factor only for gout. In particular, from the perspective of occupational environment medicine, hyperuricemia should be managed in individuals who are likely to be exposed to lead over a longer period of time for occupational and environmental reasons. The results of this study suggest that a risk for hyperuricemia exists even at low blood lead concentrations. Thus, it is necessary to conduct a large-scale prospective study to identify any causal relationship.

\section{Competing interests}

The authors declare that they have no competing interests.

\section{Authors' contributions}

$\mathrm{DL}$ and WJC designed the research and performed the statistical analysis. JSO, MKY and SWH collected the data. JWY and SHH revised the manuscript. All of the authors read and approved the final manuscript.

Received: 31 May 2013 Accepted: 13 September 2013

Published: 25 October 2013

\section{References}

1. Statistics Korea: Causes of Death Statistics in 2011. Korea; 2011

2. Ministry of Employment and Labor: Analysis of the industrial disaster status in Korea 2011. Korea; 2011.

3. Dekker JM, Girman C, Rhodes T, Nijpels G, Stehouwer CD, Bouter LM, Heine $\mathrm{RJ}$ : Metabolic syndrome and 10-year cardiovascular disease risk in the hoorn study. Circulation 2005, 112:666-673.

4. Chan WP, Sverdlov AL, Horowitz JD: Management of the metabolic syndrome in cardiovascular disease. Curr Treat Options Cardiovasc Med 2008, 10:27-38.

5. Feig DI, Kang DH, Johnson RJ: Uric acid and cardiovascular risk. N Engl J Med 2008, 359:1811-1821.

6. Baker JF, Krishnan E, Chen L, Schumacher HR: Serum uric acid and cardiovascular disease: recent developments, and where do they leave us? Am J Med 2005, 118:816-826.

7. Weaver VM, Jaar BG, Schwartz BS, Todd AC, Ahn KD, Lee SS, Wen J, Parsons PJ, Lee BK: Associations among lead dose biomarkers, uric acid, and renal function in Korean lead workers. Environ Health Perspect 2004, 113:36-42.

8. Shadick NA, Kim R, Weiss S, Liang MH, Sparrow D, Hu H: Effect of low level lead exposure on hyperuricemia and gout among middle aged and elderly men: the normative aging study. J Rheumatol 2000, 27:1708-1712.

9. Lin JL, Tan DT, Ho HH, Yu CC: Environmental lead exposure and urate excretion in the general population. Am J Med 2002, 113:563-568.

10. Occupational safety and health team of Gyeonggi seobu area office: KOSHA. Korea: Survey on the status of using lead and its compounds in Korea; 2008.

11. International Diabetes Federation: The IDF consensus worldwide definition of the metabolic syndrome. 2005. http://www.idf.org.

12. Lee K: Relationship between uric acid and hepatic steatosis among Koreans. Diabetes Metab 2009, 35:447-451.

13. Mazzali M, Kanellis J, Han L, Feng L, Xia YY, Chen Q, Kang DH, Gordon KL, Watanabe S, Nakagawa T, Lan HY, Johnson RJ: Hyperuricemia induces a primary renal arteriolopathy in rats by a blood pressure-independent mechanism. Am J Physiol Renal Physiol 2002, 282:991-997.

14. Sundstrom J, Sullivan L, D'Agostino RB, Levy D, Kannel WB, Vasan RS: Relations of serum uric acid to longitudinal blood pressure tracking and hypertension incidence. Hypertension 2005, 45:28-33. 
15. Feig DI, Nakagawa T, Karumanchi SA, Oliver WJ, Kang DH, Finch J, Johnson $\mathrm{RJ}$ : Hypothesis: uric acid, nephron number, and the pathogenesis of essential hypertension. Kidney Int 2004, 66:281-287.

16. Hwang S, Lee KE, Lee BH, Gwak J-I, Yoo J-H, Choi Y-H: Relationship between serum uric acid level and hypertension: a retrospective cohort study. Korean J Fam Med 2010, 31:672-678. Korean.

17. Feig DI, Soletsky B, Johnson RJ: Effect of allopurinol on blood pressure of adolescents with newly diagnosed essential hypertension: a randomized trial. JAMA 2008, 300:924-932.

18. Khosla UM, Zharikov S, Finch JL, Nakagawa T, Roncal C, Mu W, Krotova K, Block ER, Prabhakar S, Johnson RJ: Hyperuricemia induces endothelial dysfunction. Kidney Int 2005, 67:1739-1742.

19. Yoo TW, Sung KC, Shin HS, Kim BJ, Kim BS, Kang JH, Lee MH, Park JR, Kim H, Rhee EJ, Lee WY, Kim SW, Ryu SH, Keum DG: Relationship between serum uric acid concentration and insulin resistance and metabolic syndrome. Circ J 2005, 69:928-933.

20. Nakanishi N, Okamoto M, Yoshida H, Matsuo Y, Suzuki K, Tatara K: Serum uric acid and risk for development of hypertension and impaired fasting glucose or type II diabetes in Japanese male office workers. Eur J Epidemiol 2003, 18:523-530.

21. Li Q, Yang Z, Lu B, Wen J, Ye Z, Chen L, He M, Tao X, Zhang W, Huang Y, Zhang Z, Qu S, Hu R: Serum uric acid level and its association with metabolic syndrome and carotid atherosclerosis in patients with type 2 diabetes. Cardiovasc Diabetol 2011, 10:1-7.

22. Shabana S, Sireesha M, Satyanarayana U: Uric acid in relation to type 2 diabetes mellitus associated with hypertension. J Clin Diag Res 2012, 6:1140-1143.

23. Heimbach EJ, Bowden RG, Griggs JO, Beaujean AA, Doyle El, Doyle RD: The effects of lowering uric acid levels using allopurinol on components of metabolic syndrome. Cardiol Res 2012, 3:80-86.

24. Nakagawa T, Hu H, Zharikov S, Tuttle KR, Short RA, Glushakova O, Ouyang X, Feig DI, Block ER, Herrera-Acosta J, Patel JM, Johnson RJ: A causal role for uric acid in fructose-induced metabolic syndrome. Am J Physiol Renal Physiol 2006, 290:625-631.

25. Lanaspa MA, Sanchez-Lozada LG, Choi YJ, Cicerchi C, Kanbay M, RoncalJimenez CA, Ishimoto T, Li N, Marek G, Duranay M, Schreiner G, RodriguezIturbe B, Nakagawa T, Kang DH, Sautin YY, Johnson RJ: Uric acid induces hepatic steatosis by generation of mitochondrial oxidative stress: potential role in fructose -dependent and -independent fatty liver. J Biol Chem 2012, 287:40732-40744.

26. Song JS: Clinical manifestations and diagnosis of gout. J Korean Med Assoc 2010, 53:695-704. Korean.

27. Gil-Campos M, Aguilera CM, Canete R, Gil A: Uric acid is associated with features of insulin resistance syndrome in obese children at prepubertal stage. Nutr Hosp 2009, 24:607-613.

28. Baldwin W, McRae S, Marek G, Wymer D, Pannu V, Baylis C, Johnson RJ, Sautin $Y Y$ : Hyperuricemia as a mediator of the proinflammatory endocrine imbalance in the adipose tissue in a murine model of the metabolic syndrome. Diabetes 2011, 60:1258-1269.

29. Petersen KF, Befroy D, Dufour S, Dziura J, Ariyan C, Rothman DL, DiPietro L, Cline GW, Shulman GI: Mitochondrial dysfunction in the elderly: possible role in insulin resistance. Science 2003, 300:1140-1142.

30. Centers for Disease Control and Prevention (CDC): Adult blood lead epidemiology and surveillance-United States, 2005-2007. Morb Mortal Wkly Rep 2009, 58:365-369.

31. Centers for Disease Control and Prevention (CDC): Low level lead exposure harms children: a renewed call for primary prevention. USA; 2012.

32. Alvarez-Lario B, Macarron-Vicente J: Uric acid and evolution. Rheumatology (Oxford) 2010, 49:2010-2015.

33. de Oliveira EP, Burini RC: High plasma uric acid concentration: causes and consequences. Diabetol Metab Syndr 2012, 4:1-7.

34. Kim Y, Lee BK: Associations of blood lead, cadmium, and mercury with estimated glomerular filtration rate in the Korean general population: analysis of 2008-2010 Korean national health and nutrition examination survey data. Environ Res 2012, 118:124-129.

35. Gonick HC: Nephrotoxicity of cadmium \& lead. Indian J Med Res 2008 , 128:335-352.

36. Missoun F, Slimani $M$, Aoues A: Toxic effect of lead on kidney function in rat wistar. Afr J Biochem Res 2010, 4:21-27.
37. Krishnan E, Lingala B, Bhalla V: Low-level lead exposure and the prevalence of gout: an observational study. Ann Intern Med 2012, 157:233-241.

38. Haj Mouhamed D, Ezzaher A, Neffati F, Douki W, Gaha L, Najjar MF: Effect of cigarette smoking on plasma uric acid concentrations. Environ Health Prev Med 2011, 16:307-312

39. Petta S, Cammà C, Cabibi D, Di Marco V, Craxì A: Hyperuricemia is associated with histological liver damage in patients with non-alcoholic fatty liver disease. Aliment Pharmacol Ther 2011, 34:757-766.

40. Shiraishi $\mathrm{H}$, Une $\mathrm{H}$ : The effect of the interaction between obesity and drinking on hyperuricemia in Japanese male office workers. J Epidemiol 2009, 19:12-16.

41. Gu DC, Lee JH, Han A, Kim HJ, Lee SY, Yun SY, Lee CK: Lead exposure status of smelt process workers in steelmaking using scrap iron. $J$ Korean Soc Occup Environ Hygiene 2013, 23:164-168.

42. Choi JW, Kim NS, Cho KS, Ham JO, Lee BK: The change of air lead concentrations in litharge making and smelting industries. J Korean Soc Occup Environ Hyg 2010, 20:10-18.

43. Kim Y, Lee H, Lee CR, Park DU, Yang JS, et al: Evaluation of lead exposure in workers at secondary lead smelters in South Korea: with focus on activity of erythrocyte pyrimidine 5'-nucleotidase(P5N). Sci Total Environ 2002, 286:181-189.

44. Tong S, von Schirnding YE, Prapamontol T: Environmental lead exposure: a public health problem of global dimensions. Bull World Health Organ 2000, 78:1068-1077.

doi:10.1186/2052-4374-25-27

Cite this article as: Lee et al:: The Relevance of Hyperuricemia and Metabolic Syndrome and the Effect of Blood Lead Level on Uric Acid Concentration in Steelmaking Workers. Annals of Occupational and

Environmental Medicine 2013 25:27.

\section{Submit your next manuscript to BioMed Central and take full advantage of:}

- Convenient online submission

- Thorough peer review

- No space constraints or color figure charges

- Immediate publication on acceptance

- Inclusion in PubMed, CAS, Scopus and Google Scholar

- Research which is freely available for redistribution 